\title{
Antonio Enríquez, Felipe Pastor y san Ángel predicando: un cuadro desconocido en la colección del Museo Regional de Guadalajara
}

\section{Antonio Enríquez, Felipe Pastor and St. Angelus Preaching: An Unknown Painting in the Collection of the Museo Regional de Guadalajara}

Artículo recibido el 29 de julio de 2019; devuelto para revisión el I7 de abril de 2020; aceptado el I de junio de 2020; https://doi.org/IO.2220I/iie.I8703062e.2020.II7.2733

Alena Robin Western University, Canadá, arobin82@uwo.ca, alena.robin@gmail.
com, https://orcid.org/oooo-ooo3-3997-I472

Publicación más relevante Las capillas del Via Crucis de la Ciudad de México: arte, patrocinio y sacralización del espacio (México: Universidad Nacional Autónoma de México-Instituto de Investigaciones Estéticas, 20I4).

Líneas de investigación Arte novohispano; Pasión de Cristo; presencia del arte de América Latina en Canadá.

Lines of research New Spanish art; Passion of Christ; presence of art from Latin America in Canada.

Resumen El texto presenta un cuadro novohispano firmado por Antonio Enríquez, pintor activo a mediados del siglo XviII en la ciudad de Guadalajara. El lienzo de grandes dimensiones pertenece a la colección del Museo Regional de Guadalajara, pero hasta hace poco se guardaba en la bodega, seccionado en dos, olvidado por los especialistas del campo y el público en general. El propósito de esta nota es dar a conocer el cuadro y su iconografía, proporcionando también datos sobre el pintor que la realizó y su posible mecenas. Actualmente la obra está siendo intervenida por la Escuela de Conservación y Restauración de Occidente con el propósito de exhibirla al público.

Palabras clave Antonio Enríquez; Felipe Pastor; san Ángel; Museo Regional de Guadalajara; pintura novohispana; carmelitas.

Abstract This essay presents a painting from New Spain signed by Antonio Enríquez, a painter active in the city of Guadalajara, during the mid-Eighteenth century. The work, of large dimensions, belongs to 
the collection of the Regional Museum of Guadalajara, but until very recently was kept in the museum reserve, divided into two parts and forgotten by specialists in the field and unknown to the general public. The purpose of this note is to provide information on the painting, its iconography, its author and also to suggest the possible patron. The work is currently under restoration at the School of Conservation and Restoration in Guadalajara, for future exhibit.

Keywords Antonio Enríquez; Felipe Pastor; Saint Angelus; Regional Museum of Guadalajara; New Spanish painting; Carmelites. 
DOI: https://doi.org/10.22201/iie.18703062e.2020.117.2733

\title{
ALENA ROBIN
}

WESTERN UNIVERSITY, CANADÁ

\section{Antonio Enríquez, Felipe Pastor y san Ángel predicando:} un cuadro desconocido en la colección
del Museo Regional de Guadalajara

\begin{abstract}
ste artículo estudia un cuadro firmado y fechado en 1747 por Antonio 1 Enríquez, un pintor activo en la segunda mitad del siglo XviII en Nueva España, principalmente en el Reino de la Nueva Galicia (figs. I y 2). El lienzo, de gran tamaño, había sido registrado en el inventario de la colección del Museo Regional de Guadalajara, realizado en 1931 por Abelardo Carrillo y Gariel, pero había permanecido en el olvido hasta ahora. ${ }^{\mathrm{I}}$ Por mucho tiempo, la pintura quedó seccionada en dos, enrollada en una esquina de la bodega del museo (fig. 3), olvidada por los especialistas y el público en general. Tras el "hallazgo" de esta importante obra, la Escuela de Conservación y Restauración
\end{abstract}

I. El cuadro está conformado por varios lienzos unidos, hoy día montados en dos bastidores separados. En total, mide aproximadamente $510 \times 330 \mathrm{~cm}$. El pintor Antonio Enríquez ha sido tema de mi investigación en los últimos ańos y estoy preparando un estudio monográfico sobre esta figura desconocida de la pintura novohispana. Para la realización de este análisis pude contar con el apoyo de una beca de investigación del Social Sciences and Humanities Research Council de Canadá, que me permitió llevar a cabo varias temporadas de trabajo de campo en México y contratar a varios alumnos de posgrado como asistentes de investigación. Debo agradecer el apoyo recibido por parte del Museo Regional de Guadalajara, así como a todo su personal, a los miembros del Seminario de Pintura Virreinal de dicho museo, a la dirección de la ECRO, a los profesores y estudiantes del Seminario-Taller de Restauración de Pintura de Caballete, en particular a Adriana Cruz Lara y Gilda Pasco. 


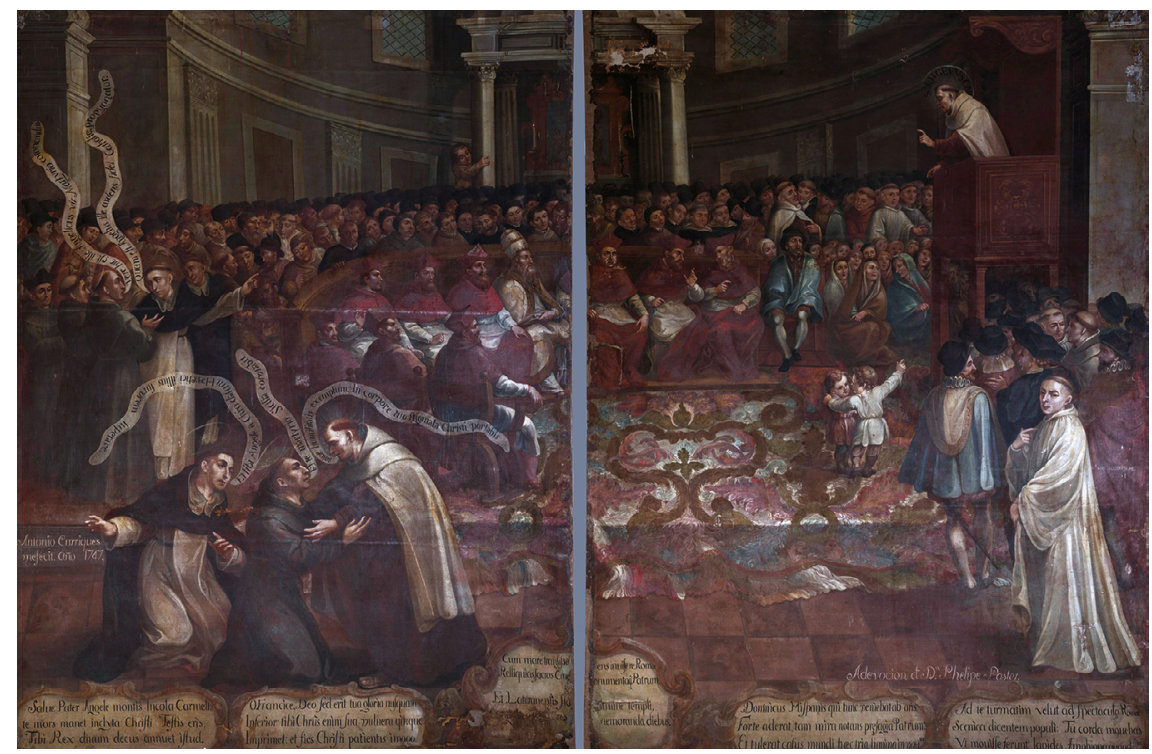

I. Antonio Enríquez, San Ángel carmelita predicando en la basílica de San Juan de Letrán, I747, óleo sobre lienzo, $5 \mathrm{IO} \times 330 \mathrm{~cm}$, Museo Regional de Guadalajara (dos bastidores unidos) (C) Gerardo Hernández Rosales, ecro. secretaría de Cultura-inaH-méx. "Reproducción autorizada por el Instituto Nacional de Antropología e Historia”.

de Occidente (ECRO) está realizando en la actualidad labores de consolidación, conservación y restauración de la misma. El objetivo de este artículo es dar a conocer la pintura y su compleja iconografía en relación con el establecimiento de la orden carmelita en la ciudad de Guadalajara. También se mencionará brevemente al pintor novohispano Antonio Enríquez, autor de dicha composición. Por último, se abordarán cuestiones de mecenazgo, pues una inscripción del cuadro alude al posible comitente de la pintura (fig. 4).

Como lo ha confirmado la exposición Pintado en México, I700-I79o, existe un enorme patrimonio del México virreinal aún por catalogar, estudiar y dar a conocer al público. ${ }^{2}$ El redescubrimiento de obras virreinales notables y de gran formato no es algo inusitado en la historiografía reciente de la pintura novohispana.

2. Fomento Cultural Banamex/Los Angeles County Museum/The Metropolitan Museum of Art, 2017-2018. Véase Pintado en México, pinxit mexici (catálogo de la exposición) (Ciudad de México y Los Ángeles: Fomento Cultural Banamex/ Los Angeles County Museum, 2018). 


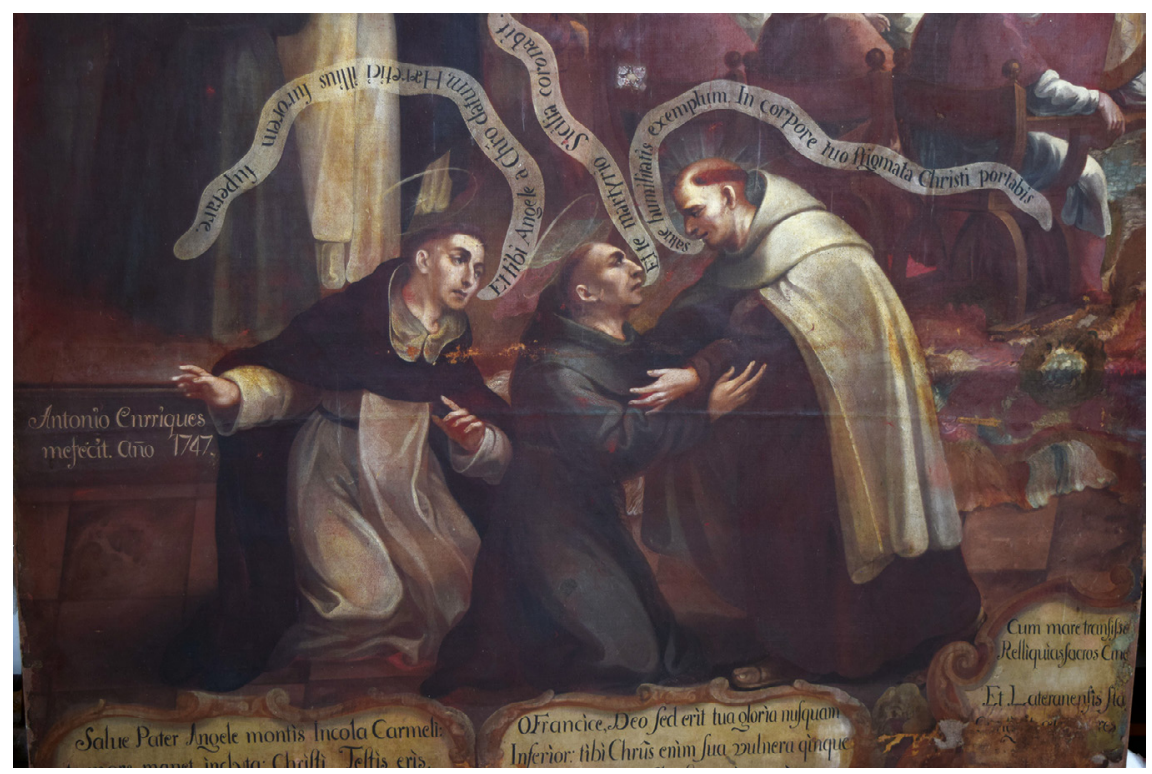

2. Detalle de la firma y del abrazo de santo Domingo, san Francisco y san Ángel. Antonio Enríquez, San Ángel carmelita predicando en la basílica de San Juan de Letrán. () Alena Robin. SECRETARÍA DE CUltura-INAH-MÉx. "Reproducción autorizada por el Instituto Nacional de Antropología e Historia”.

El propio Museo Regional de Guadalajara no es ajeno a este fenómeno pues, entre las actividades para celebrar su centenario de existencia en 20I8, emprendió el estudio de su colección de pintura virreinal. ${ }^{3}$ El presente artículo propone rescatar la memoria de un maestro casi olvidado por la historiografía de la pintura novohispana, que desarrolló en la ciudad de Guadalajara gran parte de su

3. Sobre la constitución, problemas de catalogación y posibilidades de estudio de esta colección véase Adriana Cruz Lara Silva, "Entre lo universal y lo nacional. La formación de la Pinacoteca del Museo Regional de Guadalajara”, Antropología. Revista Interdisciplinaria del INAH, núm. 3 (20I7): I8-3I. También vale la pena destacar el trabajo de la misma autora sobre la documentación, valoración y atribución al pintor sevillano Esteban Márquez de Velasco (I652-1696) de una serie de cuadros de esta misma colección; serie atribuida erróneamente a Bartolomé Esteban Murillo (I6I7-I682). Véase Adriana Cruz Lara Silva, "De Sevilla al Museo Regional de Guadalajara. Atribución, valoración y restauración de una serie pictórica franciscana”, tesis de doctorado en Historia del Arte (Universidad Nacional Autónoma de México-Facultad de Filosofía y Letras, 20I4). 


\section{ALENA ROBIN}

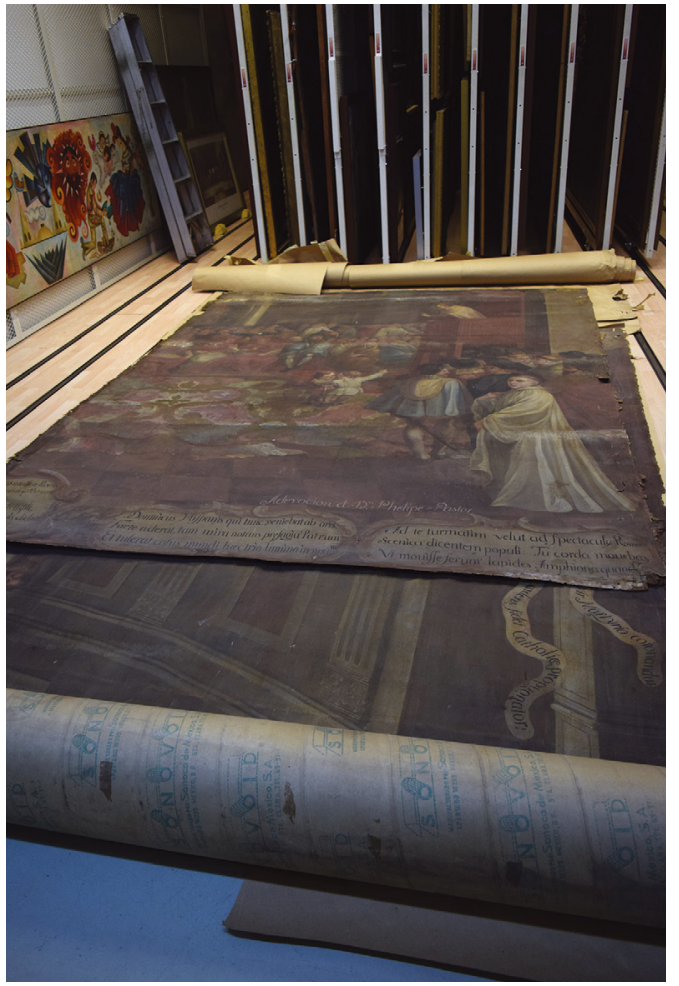

3. Detalle del estado de resguardo anterior. Antonio Enríquez, San Ángel carmelita predicando en la basilica de San Juan de Letrán. (C) Alena Robin. SECRETARÍA DE CULTURA-INAH-MÉx. "Reproducción autorizada por el Instituto Nacional de Antropología e Historia”.

obra, parte de la cual está hoy día albergada en la colección del Museo Regional de Guadalajara, a pesar de encontrarse en bodega, por diferentes razones.

\section{Antonio Enríquez}

Antonio Enríquez fue un pintor activo en la ciudad de Guadalajara desde la década de 1740. Guadalajara era entonces la capital política y religiosa del área conocida como el Reino de Nueva Galicia; tenía una ubicación céntrica en el virreinato y su extenso territorio se caracterizaba por actividades de comercio, minería, agricultura y ganadería. ${ }^{4}$ Si bien la escuela de pintura de la Ciudad de

4. El Reino de Nueva Galicia cubría una vasta extensión de territorio novohispano que corresponde a los actuales estados de Jalisco, Nayarit, Aguascalientes, Zacatecas y Colima. Una 


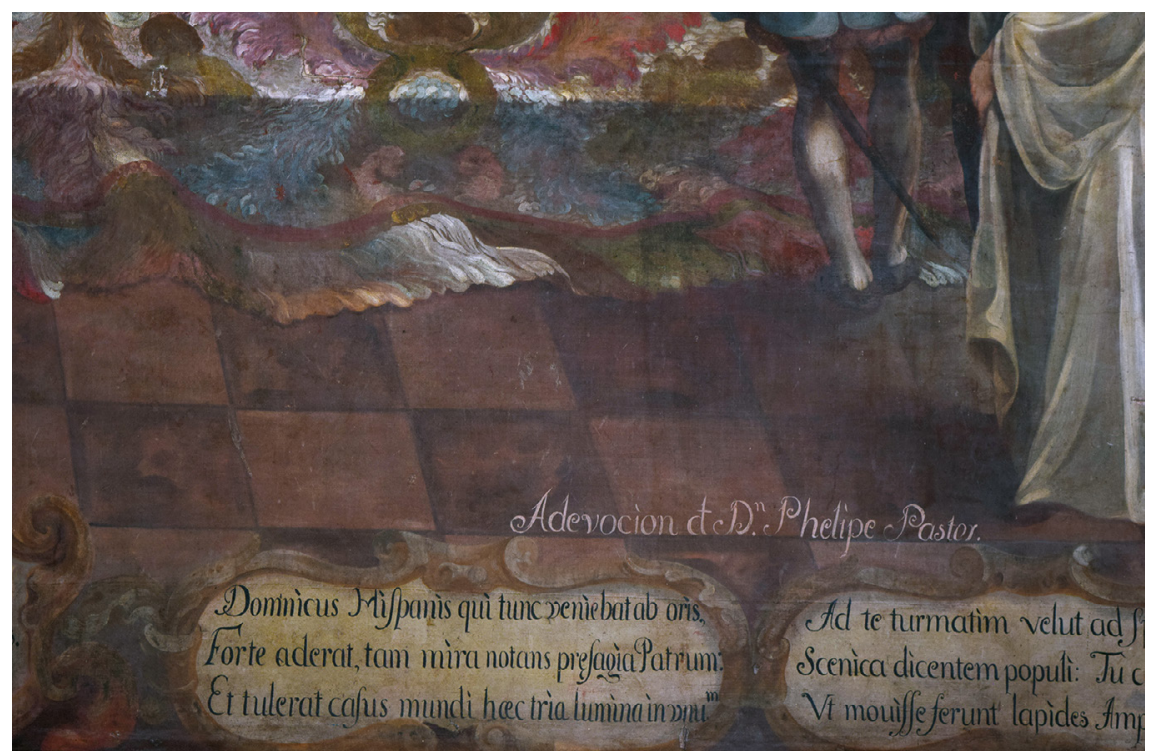

4. Detalle de la anotación del patrocinio “Adevocion de D.” Phelipe Pastor”. Antonio Enríquez, San Ángel carmelita predicando en la basílica de San Juan de Letrán. (C) Alena Robin. SECretaría DE CUlTURA-INAH-MÉx. "Reproducción autorizada por el Instituto Nacional de Antropología e Historia”.

México, capital del virreinato de Nueva España, fue la más activa durante la época colonial y es hoy día la más estudiada, no fue el único centro productor. En tiempo reciente, varios especialistas se han interesado en lo que estaba ocurriendo en otras áreas del virreinato en cuanto a producción pictórica, como en Puebla de los Ángeles, o en Oaxaca. En Nueva Galicia, la figura de Diego de Cuentas (1654-1744) es tal vez la más conocida; Francisco de León y Manuel Montes también son pintores que desarrollaron obra considerable en la región por lo que la escuela pictórica de Guadalajara también amerita más atención. ${ }^{5}$

reciente antología de textos sobre esta región se encuentra en: Thomas Calvo y Aristarco Regalado Pinedo, coords., Historia del Reino de la Nueva Galicia (Guadalajara: Universidad de Guadalajara/Centro Universitario de Ciencias Sociales y Humanidades, 2016).

5. María Laura Flores Barba, "Diego de Cuentas, pintor de entresiglos en la Nueva Galicia (I654-I744)", tesis de maestría en Historia del Arte (Ciudad de México: Universidad Nacional Autónoma de México-Facultad de Filosofía y Letras, 2013); hay datos sueltos y obras registradas en la región en: Leopoldo Orendáin, Pintura. Siglos XVI, XVII y XVIII (Guadalajara: Offset Diana, 1960). Sobre este tema, también está en desarrollo el trabajo de María Laura Flores 
Documentar la vida de Enríquez no ha sido fácil: hasta la fecha no se cuenta con evidencia de contratos con discípulos ni para obras específicas; todavía se desconocen sus datos biográficos, como su nacimiento, matrimonio o muerte. Sin embargo, diferentes documentos atestiguan la actividad de Antonio Enríquez en Guadalajara entre 1747 y 1760 , ya que es mencionado como "maestro pintor" y "vecino" de la ciudad. ${ }^{6}$ Las razones que pueden explicar la falta de información sobre Antonio Enríquez pueden ser varias, desde la catalogación de los fondos que no agiliza las búsquedas, el estado de conservación de los documentos virreinales y la poca valoración que se hizo de estos documentos por mucho tiempo, y ciertos fondos que no son de consulta pública. Esta situación no es exclusiva de Antonio Enríquez o de la región de Guadalajara, más bien se trata de una situación generalizada en el arte novohispano, con algunas excepciones. En general, se puede decir que los archivos de otras ciudades, a diferencia de la Ciudad de México, están incompletos, no se encuentran totalmente catalogados y algunos son de difícil acceso. Otra causa es que en Guadalajara, así como en otras ciudades del virreinato, no se ha localizado evidencia del establecimiento formal de un gremio de pintores equivalente al de la Ciudad de México, por lo que no se tienen documentos que hablen directamente de la actividad de los pintores. ${ }^{7}$

En la historiografía de la pintura novohispana, Manuel Toussaint se refiere a Antonio Enríquez en dos ocasiones. Primero en Arte colonial en México, publicado originalmente en 1948, donde incluye breves noticias de Antonio Enríquez, en una sección dedicada a la pintura de las provincias de Nueva España en el siglo XviII. Antonio Enríquez es registrado en la sección de Guadalajara. Lo menciona como "artista local", y reconoce a la vez que este calificativo es dudoso: supone que Antonio era tapatío puesto que de su pincel sólo se localizan

Barba, "Mexican Colonial Painters From I650 to 1750: Artistic Networks and the Production of Space", tesis de doctorado en Estudios Hispánicos (Londres, Ontario: Western University).

6. Véase, por ejemplo, el Archivo Histórico de la Real Audiencia de Guadalajara (en adelante ARAG), Bienes de difuntos, caja 289, exp. II, I747, progresivo 3228, ff. 8r y ss.; ARAG, Bienes de difuntos, caja 275, exp. 8, 1749, progresivo 3013 , f. $7 \mathrm{v}$ y ss.

7. Se han consultado varios fondos documentales en busca de Antonio Enríquez, entre ellos: los archivos de varias parroquias por medio de la base de datos de Family Search, el Archivo General de la Nación (en adelante AGN), el Archivo Histórico de la Real Audiencia de Guadalajara (ARAG), los protocolos notariales en el Archivo Histórico de Jalisco (AHJ), el Archivo Histórico de la Arquidiócesis de Guadalajara (AHAG) y el Archivo Histórico de las Dominicas en su convento. 
obras en esta ciudad, aunque se limita a citar obras que pertenecen al Museo del Estado (ahora Museo Regional de Guadalajara); no cita ninguna obra de él en las iglesias de la localidad. ${ }^{8}$ En Pintura colonial en México, Toussaint se refiere de nuevo a Antonio Enríquez, en un capítulo dedicado a la pintura dieciochesca en otras provincias de Nueva España. ${ }^{9}$

En el catálogo de la exposición Painting a New World: Mexican Art and Life, I52I-I82I (2004), Clara Bargellini se refiere a dos obras de temas mitológicos, firmada y fechada una de ellas por Antonio Enríquez; la segunda se atribuyó al mismo pintor. ${ }^{10}$ La autora subraya la temática poco común en la pintura novohispana, pero el examen de los cuadros se detiene en el análisis iconográfico de los mismos y su fuente en grabados de composiciones del pintor italiano Francesco Albani. En este estudio, las noticias biográficas de Enríquez se resumen a un breve párrafo, que hace alusión a otro cuadro de fechas mucho más tardías y de temática muy diferente, Cristo coronado y adorado por ángeles de 1786 en el Museo de Actopan (Hidalgo), por lo que la autora avanza la posibilidad de la existencia de dos pintores con el mismo nombre en la Nueva España. ${ }^{\text {II }}$ En otro estudio de la misma autora, se regresa sobre Antonio Enríquez, al hacer referencia a la manera de firmar que ostenta el cuadro del Museo de Actopan, la cual, según Clara Bargellini, ubica a Enríquez en el contexto de la toma de conciencia del valor de su oficio por parte de algunos pintores dieciochescos. ${ }^{\mathrm{I}}$

Al estudiar a Antonio Enríquez no se le puede desligar de la mención de otro pintor dieciochesco, de quien también hace falta estudiar a fondo su vida y obra, con el cual Antonio comparte el apellido: Nicolás Enríquez. La

8. Manuel Toussaint, Arte colonial en México (Ciudad de México: Universidad Nacional Autónoma de México-Instituto de Investigaciones Estéticas, 1990), I77-I78.

9. Manuel Toussaint, Pintura colonialen México, ed. Xavier Moyssén (Ciudad de México: Universidad Nacional Autónoma de México-Instituto de Investigaciones Estéticas, 1990), I86-I87.

Io. En una visita al Denver Art Museum se pudo confirmar que ambos lienzos están firmados y fechados por Antonio Enríquez. Agradezco a Donna Pierce y Julie Wilson por su apoyo.

II. Clara Bargellini, "Antonio Enríquez, Homage to Venus", Painting a New World: Mexican Art and Life, IS2I-I82I (Denver: Denver Art Museum, 2004), 203-205.

I2. Clara Bargellini, "Consideraciones acerca de las firmas de los pintores novohispanos", $E l$ proceso creativo, ed. Alberto Dallal (Ciudad de México: Universidad Nacional Autónoma de México-Instituto de Investigaciones Estéticas, 2006), 22I-222. La firma se lee de la siguiente manera: "A[d]oramoste y vendecimoste Dios y Señor Rey de la eterna Gloria/ Un Padre nro y Ave Maria por las Almas del Purgatorio/ A devoción de Antonio Enriques su Autor se dedicó día 4/ de abril de I786". 
posible relación de parentesco entre Nicolás y Antonio Enríquez es un asunto que merece atención. De hecho, Leopoldo Orendáin menciona a varios pintores que comparten el mismo apellido: "Durante el siglo XVIII existieron varios pintores apellidados Enríquez: Blas, José, Nicolás y Antonio, al que se confunde con el anterior que fue el más conocido." ${ }^{\text {13 }}$ Varias son las dinastías de pintores que se transmitieron el oficio en subsecuentes generaciones en la Nueva España. Son muy pocas las fuentes históricas conocidas por el momento que aluden a un vínculo entre Nicolás y Antonio. El padre de Nicolás Enríquez se llamaba Antonio, eso se conoce por el acta de bautismo de Nicolás del I3 de septiembre de 1704, pero no se especifica el oficio de Antonio "padre". ${ }^{14}$ Nicolás y Antonio Enríquez, quizás al pintor que más adelante desarrolló su obra en Guadalajara, están asimismo profesionalmente asociados cuando firmaron en 1728 , junto con otros pintores, un documento en relación a los intentos de los hermanos Rodríguez Juárez de regular mejor el oficio de la pintura en la Ciudad de México. ${ }^{{ }^{5}}$ El que aparezcan juntos al firmar el documento no necesariamente implica que sean parientes, pero no deja de llamar la atención que dos pintores novohispanos contemporáneos del mismo apellido están involucrados en los mismos asuntos relacionados con el oficio de ser pintor en la Ciudad de México. Antonio figura como hermano de Nicolás Enríquez en la obra del cronista Juan de Viera, "Razón de los pintores célebres de la América" en su Breve compendiossa narración de la ciudad de México, corte y cabeza de toda la América septentrional [1778]. Como figuran en la sección de "pintores modernos", es decir contemporáneos al autor, eso le da al autor un aspecto de testimonio de los hechos que cita. ${ }^{16}$ Por tanto, tal vez habría dos Antonio Enríquez, padre e hijo. Manuel Toussaint y Leopoldo Orendáin estudian a Nicolás y Antonio Enríquez a la par, pero nunca hacen afirmación alguna sobre el hecho de que comparten el mismo apellido, o las implicaciones que podría tener. Guillermo Tovar de Teresa reconoce que había dos pintores de apellido Enríquez,

I3. Orendáin, Pintura. Siglos XVI, XVII y XVIII, 27.

I4. Mina Ramírez Montes, "En defensa de la pintura. Ciudad de México. 1753", Anales del Instituto de Investigaciones Estéticas XXIII, núm. 78 (200I): I07, n. I4.

15. Paula Mues Orts, La libertad del pincel. Los discursos sobre la nobleza de la pintura en Nueva España (Ciudad de México: Universidad Iberoamericana, 2008), 399-40I.

I6. Reproducido en Antonio Rubial, La ciudad de México en el siglo XVIII (I690-I780), tres crónicas (Ciudad de México: Consejo Nacional para la Cultura y las Artes, 1990), 291-293. 
Antonio y Nicolás, "los cuales debieron ser hermanos, si atendemos a la cronología, pues ambos son contemporáneos" ${ }^{17}$

Si la relación entre Antonio y Nicolás resulta nebulosa, habría que agregar dos eslabones más a la ecuación de esta posible dinastía de pintores: Blas y José Enríquez. El primer hijo de Nicolás Enríquez, Blas, fue bautizado en 1726 y su padrino fue el pintor y bachiller Nicolás Rodríguez Juárez. ${ }^{18}$ Este dato resulta interesante, pues Nicolás Rodríguez Juárez también firmó las amonestaciones de casamiento de Nicolás Enríquez el 28 de enero de 1725, lo que parece sugerir una relación estrecha entre ambos. ${ }^{19}$ Así, esta relación personal podría ubicar a Nicolás en la esfera artística de los hermanos Rodríguez Juárez; tal vez se podría pensar que en este ámbito también se haya formado Antonio Enríquez, antes de dirigirse hacia Guadalajara para ejercer su oficio.

Las obras firmadas por Antonio Enríquez catalogadas por el momento oscilan entre 1732 y 1786 lo que abre la posibilidad de que se trate de obras de dos pintores homónimos. ${ }^{20}$ Las pinturas firmadas por Antonio Enríquez ilustran temas muy variados: escenas bíblicas del Antiguo y Nuevo Testamento, escenas mitológicas, santos, retratos y escenas de devoción local. La obra pictórica de Antonio Enríquez se encuentra principalmente en la ciudad de Guadalajara, y otras áreas de la entonces Nueva Galicia. Hay diversos cuadros que se ubican o proceden de diferentes templos de la ciudad; por ejemplo, el Santo Cristo de las Tres Gracias (1745, iglesia de San Juan de Dios). Dos series sobresalientes de Enríquez las patrocinaron conventos femeninos de Guadalajara: la serie del Vía Crucis de I4 grandes lienzos para el convento de Carmelitas Descalzas de Santa Teresa (ahora en el Museo Regional de Guadalajara)

17. Más adelante repite noticias de Toussaint y Orendáin sobre obras de ambos en Guadalajara, con mucha confusión en la atribución. Se ilustra la entrada de "Los Enríquez" exclusivamente con obras de Nicolás Enríquez. Véase Guillermo Tovar de Teresa, Repertorio de artistas en México, vol. I (Ciudad de México: Bbva Bancomer, 1995), 368. En la traducción al inglés de la obra, se habla de los "Enríquez brothers", lo que no aparece en español, véase Guillermo Tovar de Teresa, Repertory of Artists in Mexico, vol. I (Ciudad de México: Bbva Bancomer, 1995), 368.

I8. Archivo Histórico del Arzobispado de México (анам), Parroquia de San Miguel Arcángel, Bautizos de españoles, I716-1732, caja I42, rollo 2, vols. 3-6.

19. Archivo parroquial de San Miguel Arcángel de la Ciudad de México, Libro de amonestaciones, años 1722-1760, f. 19, citado por Mina Ramírez Montes, "En defensa de la pintura", I06-I07, n. I4. Es conocido el hecho de que, al quedar viudo en I704, Nicolás Rodríguez Juárez emprendió muy pronto la vida eclesiástica; en 1706 ya se mencionaba como bachiller, pero no por esta razón dejó de pintar.

20. Hecho ya señalado por Bargellini, "Antonio Enríquez, Homage to Venus", 203-205. 


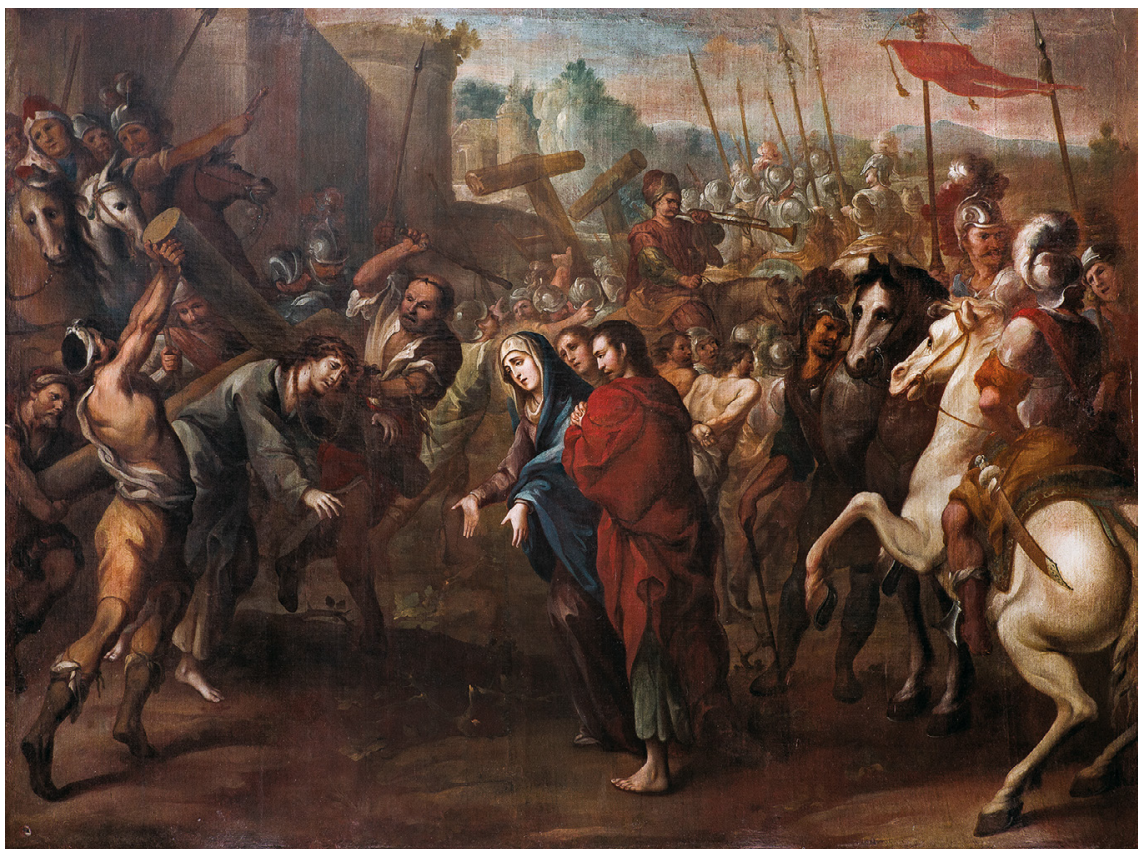

5. Antonio Enríquez, Encuentro de Jesús con su madre, serie "Vía Crucis", I742-1749, óleo sobre tela, I $86 \times 240$ cm, Museo Regional de Guadalajara. (C) Gerardo Hernández Rosales. SECretaría DE CULTURA-INAH-MÉx. "Reproducción autorizada por el Instituto Nacional de Antropología e Historia”.

(fig. 5), ${ }^{21}$ y la serie de cuatro enormes lienzos que ilustran escenas de la vida de santo Domingo de Guzmán que se conserva en el lugar para el cual fue concebida, la sacristía de la iglesia de lo que fue el poderoso convento dominico de Santa María de Gracia. El tamaño de los lienzos, así como la cantidad de cuadros que conforman ambas series permiten pensar que Antonio Enríquez tuvo un taller alrededor de él, lo que podría explicar diferentes niveles de destreza que se pueden percibir en las obras.

El pincel de Antonio Enríquez fue también apreciado en otras áreas de la Audiencia de Nueva Galicia, por ejemplo: en Lagos de Moreno (Retrato de Sor María Esthefana, ca. 1750, colección particular), en la iglesia de La Playa, en

2I. Alena Robin, "El Vía Crucis del Museo Regional de Guadalajara y los avatares del tiempo", Actas del Primer Coloquio Interdisciplinar: Museo Regional de Guadalajara hacia su Centenario. 1918-20I8 (Guadalajara: Instituto Nacional de Antropología e Historia, 2015), 35-46. 
Bolaños (Virgen de Guadalupe, I75I, Patrocinio de San José, s. f.), en Real Alto, en el actual municipio de San Sebastián del oeste (Virgen de Guadalupe, s. f.) o en Nochistlán (Ánimas del purgatorio, s. f.).22

Las fechas exactas y el contexto de la llegada de Antonio Enríquez a Guadalajara resultan aún oscuras. Aparece, sin embargo, en febrero de 1747 como un pintor maduro, registrando las pinturas en el inventario de los bienes que pertenecieron a un importante miembro de la élite local, el terrateniente, minero y comerciante Bernardo Apolinar Miranda Villaysán, propietario de la extensa hacienda El Cabezón y La Vega, al cual regresaré más adelante. ${ }^{23} \mathrm{El}$ suceso más prestigioso en el cual participó Antonio Enríquez fue sin duda la jura de Fernando VI (I713-1756) que ocurrió en Guadalajara en octubre de 1747 . Enríquez fue el encargado de realizar las pinturas alegóricas para la plaza mayor de Guadalajara para aclamar al nuevo monarca, trabajando en colaboración con la élite intelectual del momento, incluyendo el obispo Juan Gómez de Parada (I678-175I), de quien Enríquez realizó un retrato unos años después (ahora en el Museo Regional de Guadalajara). ${ }^{24}$ Del manuscrito de

22. Alena Robin, "Antonio Enríquez. Su obra pictórica en las regiones culturales de Jalisco", Actas del Tercer Coloquio Interdisciplinar: regiones culturales: sur, norte, costa y centro. Museo Regional de Guadalajara hacia su Centenario. I9I8-20I8 (Guadalajara: Instituto Nacional de Antropología e Historia, 2018), 283-297.

23. ARAG, Bienes de difuntos, caja 289, exp. II, progresivo 3228, ff. I4v-I7r, I747. Agradezco a María Laura Flores Barba por su ayuda para localizar este importante documento. En I718, Miranda Villaysán era parte del cabildo de Guadalajara, con otros importantes terratenientes locales. En 1738 , se le registra como tenedor del monopolio de la venta de carne en Guadalajara, véase Eric van Young, Hacienda and Market in Eighteenth-Century Mexico. The Rural Economy of the Guadalajara Region, I675-1820 (Berkeley: University of California Press, I98I), 50, 55, I74. Las haciendas de El Cabezón y La Vega eran dos propiedades constituidas como una sola posesión que se administraba en conjunto desde principios del siglo XviII, Van Young, Hacienda and Market, $\mathrm{I} 62$.

24. Agradezco la noticia de este importante documento a María Laura Flores Barba, así como la transcripción del mismo a Iván Baruj Vázquez Clavellina. El documento se ubica en: ARAG, Civil, caja I48, exp. 9, I791, progresivo I639, "De la relación de la Jura celebrada en esta Capital por la exaltación al Trono de S. M. el Sr. Dn. Fernando Sexto” ( 56 ff.). El documento es una copia hecha en 179I por Urbano Ballesteros de una relación de las ceremonias por el escribano del cabildo de Guadalajara, Manuel de Mena, realizada en I748. Víctor Mínguez menciona un opúsculo publicado en Guadalajara de los festejos de Fernando VI, que versa sobre los actos organizados por el gremio de los comerciantes de la ciudad quien costeó la acuñación de 900 monedas con el busto de Fernando VI que fueron repartidas, como es de costumbre, después de la proclamación. Véase Víctor Mínguez, "Reyes absolutos y ciudades leales. Las proclamaciones de Fernando VI en la Nueva España”, Tiempos de América, núm. 2 (1998): 31. Algunas monedas 
la jura al nuevo monarca emana mucha información que alude a la cultura simbólica de la sociedad de Guadalajara a mediados del siglo XvıII. También revela el aprecio que recibía Antonio Enríquez como pintor en este ambiente, pues en alguna parte del manuscrito se refiere a él como "el diestro pincel de nuestro Henrriquez". ${ }^{25}$ De esta prolífica temporada de actividades es la pintura que se relaciona con la orden carmelita masculina de Guadalajara, tema del presente artículo (fig. I).

\section{San Ángel predicando y la orden carmelita en Guadalajara}

El cuadro que me ocupa ilustra una compleja escena que se desarrolla en el interior de un templo de arquitectura clásica (fig. I). En el fondo, en la parte central, hay un altar representando a un Calvario, Cristo en la Cruz acompañado de la Virgen María y san Juan, difícil de apreciar. Del lado derecho, hay un personaje predicando en el púlpito (fig. 6). Una multitud lo escucha, tanto personajes del ámbito religioso como laico, están presentes: el papa, cardenales, frailes de distintas órdenes religiosas, señores y damas (figs. 6-7). Abajo del púlpito, dos niños se abrazan y señalan al fraile predicando (fig. 6). Unos personajes están poniendo la debida atención a la homilía, mientras otros parecen estar debatiendo entre sí. Algunos personajes están dispuestos sobre una rica alfombra. Del lado derecho, un hombre de pie con túnica blanca se señala a sí mismo, viendo directamente hacia el espectador (fig. 8). Del lado izquierdo, tres personajes se abrazan: un fraile franciscano, un carmelita y un dominico (fig. 2). De sus bocas salen filacterias con textos en latín. Dos de los mismos personajes se representan en una segunda escena detrás de la primera, señalando al carmelita que predica (fig. 7). De nuevo de sus bocas salen filacterias con texto en latín. En la parte inferior del

con la efigie de Fernando VI están reproducidas en: Manuel Romero de Terreros, "Las efigies de Fernando VI en México", Anales del Instituto de Investigaciones Estéticas VI, núm. 22 (1954): 89-9I, lám. I. Algunas noticias de la jura de Fernando VI están también registradas en: Francisco de la Maza, La mitología clásica en el arte colonial de México (Ciudad de México: Universidad Nacional Autónoma de México-Instituto de Investigaciones Estéticas, 1968), 190-199.

25. ARAG, Ramo Civil, caja I48, exp. 9, progresivo I639, I79I, f. 20 y v (bis), énfasis mío. Aquí me interesa sobre todo destacar la participación de Antonio Enríquez en las celebraciones. Para un análisis más completo de los preparativos, descripciones de las construcciones efímeras, festejos y la celebración de la jura en sí, véase Thomas Calvo, "La jura de Fernando VI en Guadalajara (1747): de la religión real a la festividad”, Takwá, núm. 8 (2005): 67-92. 


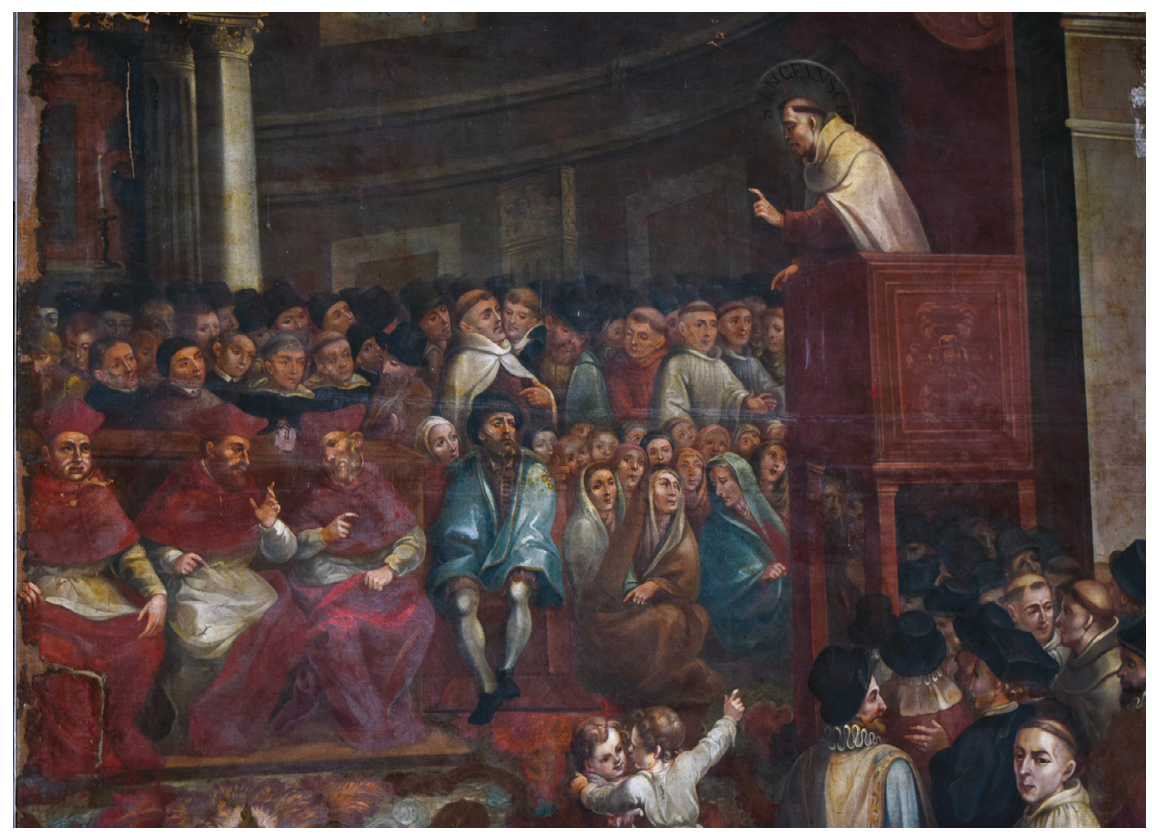

6. Detalle de san Ángel predicando y de la muchedumbre escuchando la predicación. Antonio Enríquez, San Ángel carmelita predicando en la basílica de San Juan de Letrán, (C) Alena Robin. SECRETARÍA DE CULTURA-INAH-MÉx. "Reproducción autorizada por el Instituto Nacional de Antropología e Historia”.

cuadro hay también un amplio texto en latín dividido en varias cartelas que alude a diferentes pasajes de la vida del carmelita. ${ }^{26}$

El cuadro representa el momento de la predicación de san Ángel (II85-I226) en la basílica de San Juan de Letrán en Roma, durante la cual el santo carmelita tuvo la revelación de que ahí estaban presentes san Francisco (II8I/82-I226) y santo Domingo (II7O-I22I). ${ }^{27}$ Predicó tan bien que ambos santos lo quisieron conocer. Se trata del hecho histórico del encuentro en Roma de los

26. Las inscripciones en latín han sufrido varias pérdidas debido al estado de conservación del lienzo.

27. La información sobre la vida del santo proviene de las siguientes fuentes: Joseph Diego, Tres bellas flores del Carmelo, en las vidas de sus tres héroes gloriosos S. Angelo, y san Anastasio mártires, y san Alberto, el Thaumaturgo de Sicilia. Se añaden, el novenario de este médico celestial, y el itinerario de la vida, para la muerte, que cercano a ella, dispuso, para mejor disponerse para ella (Zaragoza: Herederos de Manuel Roman, 1724); Ludovico Saggi, ed., Santos del Carmelo. Biografías de diversos diccionarios, trad. Jesús María Carrión (Madrid: Librería Carmelita- 


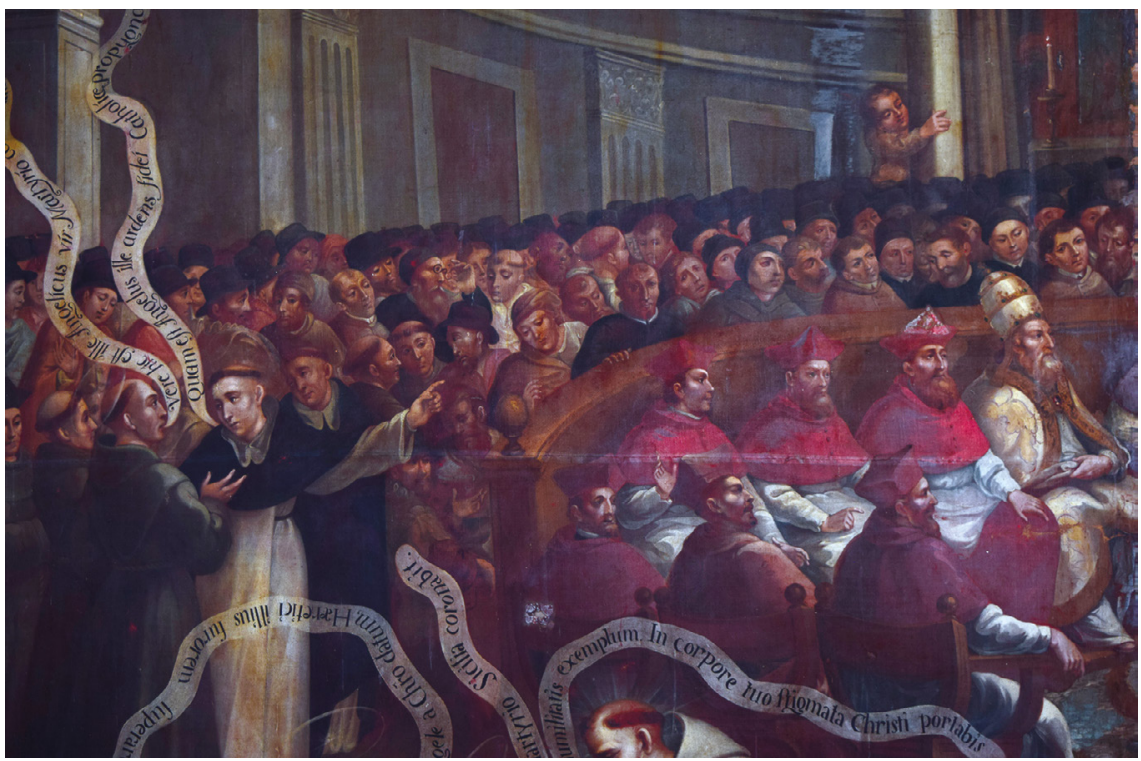

7. Detalle de la muchedumbre escuchando la predicación. Antonio Enríquez, San Ángel carmelita predicando en la basílica de San Juan de Letrán. (C) Alena Robin. SECretaría de CULTURA-INAH-MÉx. "Reproducción autorizada por el Instituto Nacional de Antropología e Historia”.

fundadores de las diferentes órdenes religiosas, momento que se ha visto como el símbolo del hermanamiento de las órdenes en su afán misionero y apostólico. Aunque es muy común la representación del abrazo entre san Francisco y santo Domingo, hubo un tercer personaje en este abrazo histórico, que ha sido silenciado por las crónicas franciscanas y dominicas.

San Ángel es un santo carmelita venerado desde I456, cuando el papa Pío II aprobó su culto. Nació en Jerusalén de padres judíos convertidos al cristianismo gracias a la aparición de la Virgen. Vivió en el Monte Carmelo, y viajó a Roma en I2I8 en compañía de otros carmelitas para obtener la aprobación de la Regla del Carmen del papa Honorio III. Fue durante su estancia en Roma que ocurrió el encuentro con san Francisco y santo Domingo, cuando san Ángel predicó en la basílica de San Juan de Letrán. Posteriormente, san Ángel fue enviado a Sicilia en misión evangelizadora. En Licata se encontró con

na, 1982), 243-247. El estudio más completo sobre san Ángel es de Ludovico Saggi, S. Angelo di Sicilia. Studio sulla vita, devozione, folklore (Roma: Institutum Carmelitanum, 1962). 
DOI: https://doi.org/10.22201/iie.18703062e.2020.117.2733

ANTONIO ENRÍQUEZ, FELIPE PASTOR Y SAN ÁNGEL PREDICANDO

8. Detalle del personaje vestido con una túnica blanca, y otro con espada. Antonio Enríquez, San Ángel carmelita predicando en la basilica de San Juan de Letrán. (C) Alena Robin. SECRETARÍA DE CULTURA-INAH-MÉx. "Reproducción autorizada por el Instituto Nacional de Antropología e Historia”.

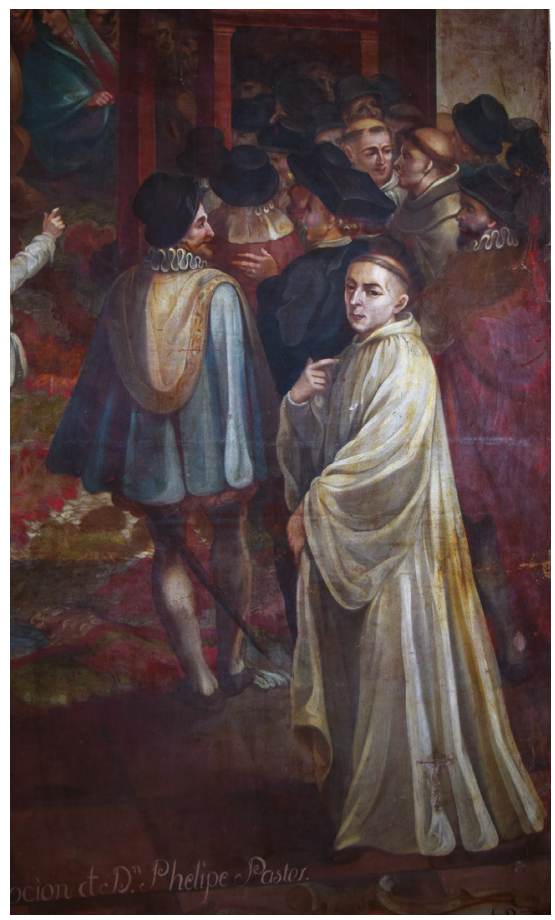

Berengario, un infiel cátaro. San Ángel convenció a su compañera de que lo dejara, lo cual hizo después de convertirse. Dicha mujer decidió después vivir una vida de penitencia, por lo que Berengario se vengó de san Ángel cuando predicaba, hiriéndole con una espada. Murió días después a causa de sus heridas. El desarrollo del culto a san Ángel va de la mano con la expansión de la orden carmelita, sobre todo en Italia. San Ángel tiene fama de haber convertido a mucha gente y haber obrado muchos milagros. En especial, se ha recurrido a su protección para las pestes. Los atributos más frecuentes de san Ángel son la vestimenta carmelita, una espada o cuchillo que se relacionan con su muerte, un libro, y tres coronas que aluden a sus cualidades de virgen, doctor y mártir. La escena pintada por Antonio Enríquez es más bien una narración de los momentos más importantes y gloriosos de la vida del santo: la predicación en Roma, y su encuentro con san Francisco y santo Domingo (fig. I). Aunque las representaciones de san Ángel en el arte novohispano no son muy abundantes, fue, no obstante, una figura respetada dentro del ámbito carmelita 
novohispano, pues se aprovechó su nombre para denominar un convento de la orden, ahora una colonia, originalmente en las afueras de la Ciudad de México.

Los primeros miembros de la orden de los carmelitas descalzos llegaron a la Nueva España en 1585 con el propósito de cumplir una misión evangelizadora que fue frustrada por diferentes razones. Por tanto, los frailes adoptaron una postura urbana contemplativa, y ofrecieron servicios pastorales a la población española en vez de estar a cargo de la doctrina indígena. Así, varias de las fundaciones carmelitas novohispanas se hicieron en un contexto de expansión territorial y fortalecimiento urbano, además de la independencia de la provincia americana respecto a la metrópolis. ${ }^{28}$

Por la temática, el cuadro de Antonio Enríquez necesariamente se relaciona con la presencia de la orden carmelita en la Nueva España y adquiere una connotación especial en el contexto de Guadalajara. El establecimiento de la rama varonil de los carmelitas en Guadalajara fue bastante complicado, pues se hizo en tres ocasiones a lo largo de varios siglos. ${ }^{29}$ El cronista Agustín de la Madre de Dios afirma que, para 1593, todas las órdenes religiosas se encontraban en Guadalajara, menos los carmelitas..$^{30}$ La primera fundación se hizo hacia I595, la segunda a mitad del siglo XVII, y fue sólo hacia mediados del siglo XVIII que se realizó la fundación definitiva. Si bien en las dos primeras ocasiones los religiosos fueron bien recibidos por el obispo, la nobleza y el pueblo, las demás órdenes religiosas celaban a los carmelitas. Aparentemente, para la tercera fundación, tanto el clero regular como el secular favorecían el regreso de los carmelitas a Guadalajara, y contaron con el apoyo económico de varios vecinos. ${ }^{31}$ Es de destacar la aportación, hacia I732, del diputado del Comercio y Real Aduana de Guadalajara, Bernardo Apolinar de Miranda Villaysán, quien apoyó con la cantidad de 30000 pesos para la fundación carmelita. ${ }^{32}$ Como ya se había mencionado, Enríquez hizo el avalúo en el inventario de bienes de

28. Jessica Ramírez Méndez, Los carmelitas descalzos en la Nueva España. Del activismo misional al apostolado urbano, 1585-1614 (Ciudad de México: Instituto Nacional de Antropología e Historia, 2015), 13-22, 206-209.

29. Manuel Ramos Medina, El Carmelo novohispano (Ciudad de México: Centro de Estudios de Historia de México Carso, 2008), 89-103.

30. Agustín de la Madre de Dios, Tesoro escondido en el Santo Carmelo mexicano, ed. Eduardo Báez Macías (Ciudad de México: Universidad Nacional Autónoma de México-Instituto de Investigaciones Estéticas, 1986), I79.

31. Ramos Medina, El Carmelo novohispano, 98-IOI.

32. Ramos Medina, El Carmelo novohispano, roo. 
este importante personaje en 1747 , lo que podría sugerir una relación estrecha entre el diputado del comercio, los carmelitas y Enríquez. El asunto de la tercera fundación empezó en 1725 y la cédula real fue finalmente expedida en abril de $1746 .{ }^{33} \mathrm{La}$ fecha de la real cédula es importante pues es el acontecimiento que más se aproxima a la datación del cuadro de Antonio Enríquez. El abrazo entre san Francisco, santo Domingo y san Ángel podría entonces hacer alusión a esta pacificación de las órdenes religiosas que permitió la tercera y definitiva fundación de la orden masculina carmelita en Guadalajara.

Las inscripciones en latín en las cinco cartelas de la parte inferior del cuadro y en las filacterias saliendo de la boca de san Francisco, santo Domingo y san Ángel aluden a la conversación mantenida entre los tres fundadores de órdenes religiosas y diversos momentos de la vida del santo carmelita. Según la tradición, Enoch, compañero de san Ángel, escribió el relato de su vida y diferentes versiones fueron publicadas entre los siglos XVI y XVIII en latín, italiano y espańol. Por el momento, no se conoce edición alguna impresa en la Nueva España, pero cualquiera de las ediciones europeas podría haber circulado en América. La versión romana de 1746 (Vita di San Angelo) es de particular interés, pues está muy cercana en el tiempo a la elaboración de la pintura de Antonio Enríquez. La abundancia de las inscripciones en latín sugiere una audiencia educada que podía leer este idioma y reflexionar sobre la vida del santo carmelita.

La narración de la escena en el cuadro empieza con la presencia del santo predicando en la esquina superior derecha (fig. 6), para seguir con la discusión entre san Francisco y santo Domingo del lado izquierdo a la mitad horizontal de la escena, que señalan hacia san Ángel (fig. 7). Termina la narrativa con el abrazo de los tres santos, en la parte inferior, del lado izquierdo (fig. 2). No parece casualidad que la firma del pintor se encuentre a un costado de esta escena, que es primordial en la composición. También es importante destacar que san Ángel se encuentra más erguido que santo Domingo y san Francisco, que están arrodillados ante el carmelita.

El pintor se esmeró en distinguir rostros, posturas y vestimentas entre los personajes que asisten a la predicación de san Ángel, individualizándolos con diferentes colores de piel, tocados, entre otros. La escena es anacrónica o ahistórica en el sentido que combina maneras de vestir de diferentes épocas. Sobresale de la muchedumbre un énfasis en las conversaciones que se llevan a cabo, por medio de una gran gesticulación. Se han calculado alrededor de 200 personas, mujeres

33. Ramos Medina, El Carmelo novohispano, I03. 
DOI: https://doi.org/10.22201/iie.18703062e.2020.117.2733

278

ALENA ROBIN

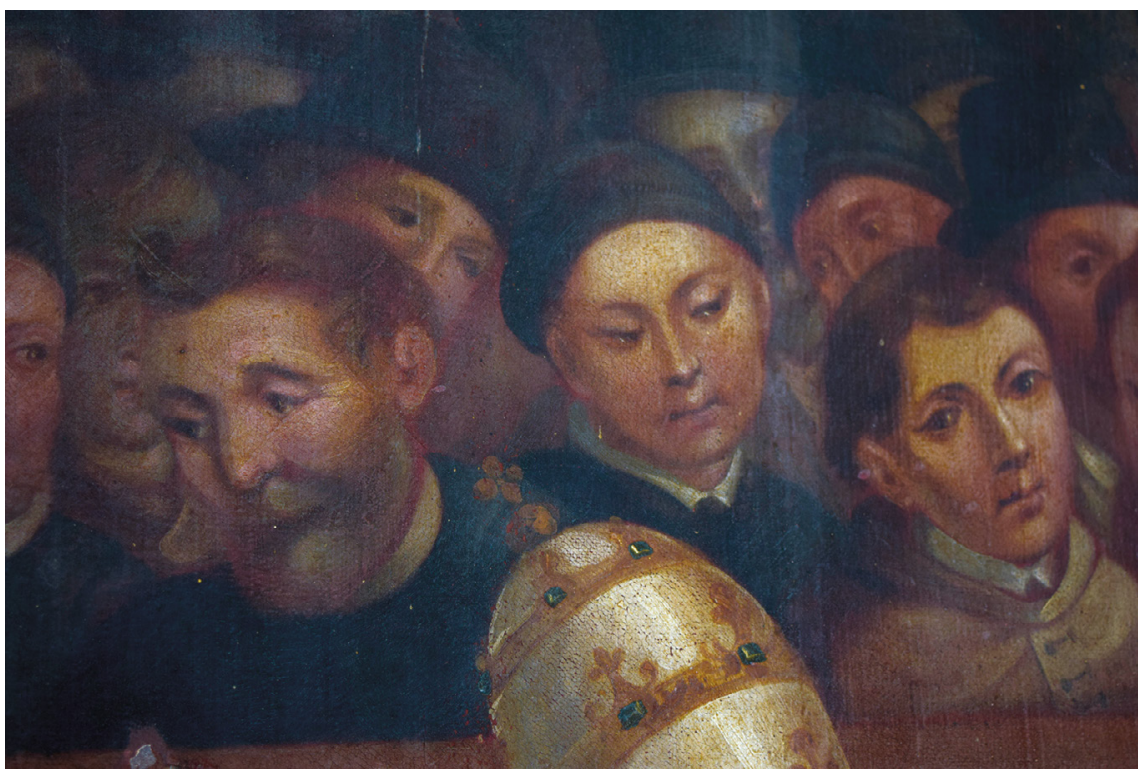

9. Detalle del personaje con rasgos asiáticos, Antonio Enríquez, San Ángel carmelita predicando en la basílica de San Juan de Letrán. (C) Alena Robin. Secretaría de Cultura-InAh-méx. "Reproducción autorizada por el Instituto Nacional de Antropología e Historia".

(I9), niños (3), cardenales (Io), un papa que sobresale por la riqueza de su atuendo y la minuciosidad de su tiara papal (fig. 7), hay varios monjes de diferentes órdenes. Sale a relucir un personaje con rasgos asiáticos (fig. 9), uno con anteojos (fig. Io), un soldado (fig. II), un civil con espada dando la espalda al público (fig. 8), y un único civil sentado al mismo nivel que los cardenales (fig. 6).

La ambientación arquitectónica de la escena está en general bien realizada en términos de perspectiva y profundidad. Hay algunos recursos que Antonio Enríquez emplea en el cuadro de san Ángel predicando que se encuentran en otras composiciones del pintor. Por ejemplo, el tema de la alfombra para llenar un espacio (figs. I y 4), también aparece en la pintura del Nacimiento de santo Domingo de Guzmán de la serie en la sacristía de la iglesia del ex convento de Santa María de Gracia. ${ }^{34}$ De la misma serie, se podría mencionar la variedad de actitudes de gesticulación y conversación de los frailes dominicos en la composición de Santo Domingo atendido por los ángeles, lenguaje que aparece de

34. Los cuadros están reproducidos en el anexo fotográfico de Orendáin, Pintura. Siglos XVI, XVII $y$ XVIII, s. p. 


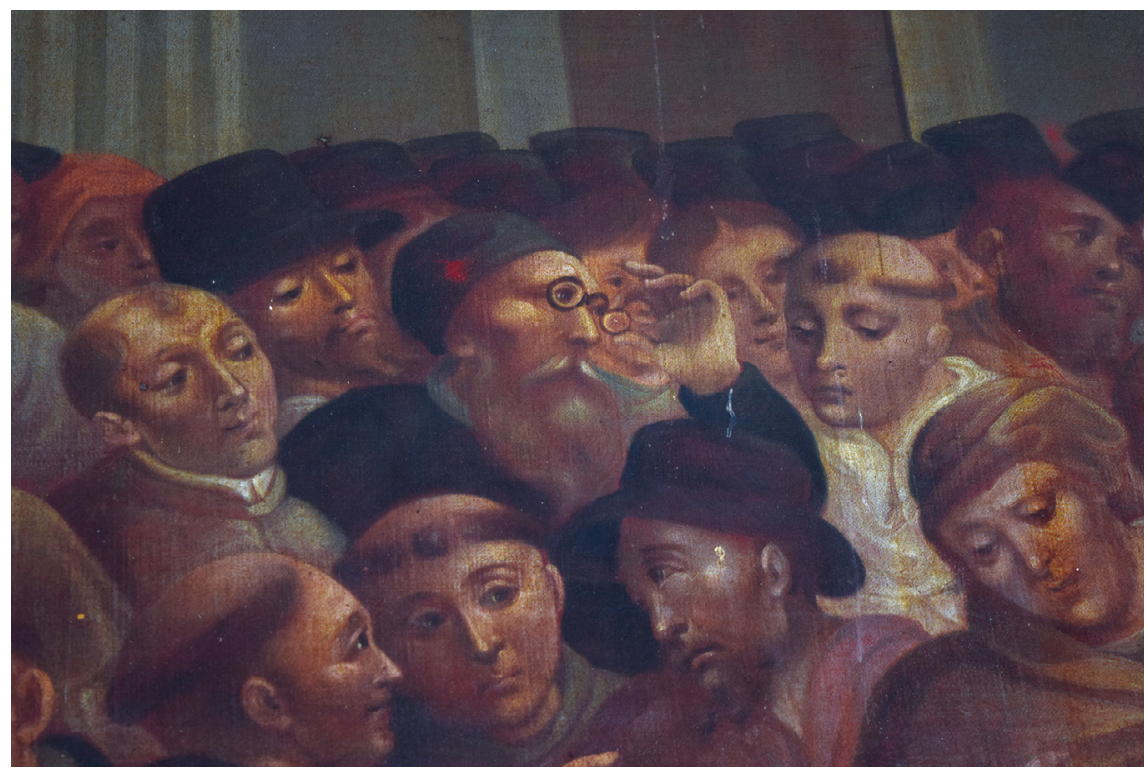

Io. Detalle del personaje con anteojos. Antonio Enríquez, San Ángel carmelita predicando en la basilica de San Juan de Letrán. (C) Alena Robin. SeCretaría de cultura-Inah-méx. "Reproducción autorizada por el Instituto Nacional de Antropología e Historia".

forma abundante en la muchedumbre que está presente en la predicación del santo carmelita (figs. 6-7). Lo mismo se reconoce en la escena del Pentecostés de la serie del Vía Crucis, hoy en el Museo Regional de Guadalajara, donde los apóstoles, dispuestos alrededor de la Virgen, conversan animosamente, en una variedad de posturas y gestos, que se asemeja al cuadro de temática carmelita. Otro recurso pictórico empleado por Antonio Enríquez con cierta recurrencia sería el de poblar el espacio con muchas personas. Una vez más de la serie de Santa María de Gracia, este procedimiento se ilustra en la escena de la Aparición de la Virgen a santo Domingo, donde tanto mujeres como hombres civiles son testigo del milagro que acontece mientras el fundador de la orden celebra misa. Las personas presentes están también individualizadas en sus vestimentas, ademanes, posturas, gestos, edades, aunque de una manera un poco más convencional que en el cuadro del Museo Regional de Guadalajara. Varios cuadros de la serie del Vía Crucis también implican la presencia de muchas personas; por ejemplo, en esta escena del Encuentro de Jesús con su madre (fig. 5), donde además de la Virgen y san Juan, está presente una numerosa cantidad 
de personas, tanto autoridades civiles y militares, como sayones. Estos ejemplos de recursos pictóricos utilizados por Antonio Enríquez se encuentran en sus escenas de gran formato y son elementos a los cuales acude el maestro pintor para activar la narración de las escenas representadas.

Debe destacarse la presencia de dos niños en la composición de la sacristía de Santa María de Gracia, recurso que también se encuentra en la escena de la predicación de san Ángel (figs. 6-7). La inclusión de los dos niños abrazándose en este espacio no resulta del todo clara (fig. 6). Uno de ellos señala a san Ángel, mientras los nińos parecen estar conversando entre ellos. En parte es un recurso pictórico que invita al concurrente a participar de los eventos ahí representados, pero también podría ser referencia a un episodio en particular de la vida del santo carmelita, no identificado por el momento. Un tercer niño se encuentra entre la multitud de la gente conglomerada, sosteniéndose de una columna, viendo hacia el predicador (fig. 7). En su análisis de un cuadro de Giotto de una escena de san Francisco, Moshe Barasch propone que la presencia de niños asumiría el valor de testigos de los hechos acontecidos, subrayando la importancia de los gestos sobre la palabra, para agilizar la memoria de los niños. ${ }^{35}$ De una manera similar, en el cuadro de san Ángel por Antonio Enríquez, quedarían relacionadas ambas variables: el énfasis en los gestos de los participantes y la presencia de los nińos.

Es importante destacar que las reliquias de san Ángel se albergan en una urna de plata en la iglesia dedicada al santo carmelita en la localidad de Licata, en Sicilia. Dicha urna está conformada de escenas que ilustran diferentes pasajes de la vida del santo, y la predicación en Roma y la del martirio del carmelita se relacionan iconográficamente con la escena de la parte central del cuadro de Guadalajara. ${ }^{36}$ Las láminas de plata quizás hayan sido reproducidas mediante grabados, lo que permitió que las composiciones circularan de manera amplia más allá de Licata. Aún no se han localizado los grabados empleados por Antonio Enríquez, pero las evidencias visuales sugieren un parentesco entre la pintura y la urna. Algunos detalles del cuadro, no obstante, se distinguen del diseño de las láminas. Me gustaría sugerir que el personaje de la derecha, vestido de blanco, sea Enoch, el fiel compañero de san Ángel, testigo de los

35. Moshe Barasch, Giotto y el lenguaje del gesto (Madrid: Akal, 200I), I4-15. Agradezco esta noticia a Mirta Insaurralde.

36. Mis diversos intentos por conseguir imágenes de alta resolución de las escenas de la urna de Licata no tuvieron éxito. Las imágenes están disponibles en: http://www.lavedettaonline.it/ readarticle.php?article_id=I7 


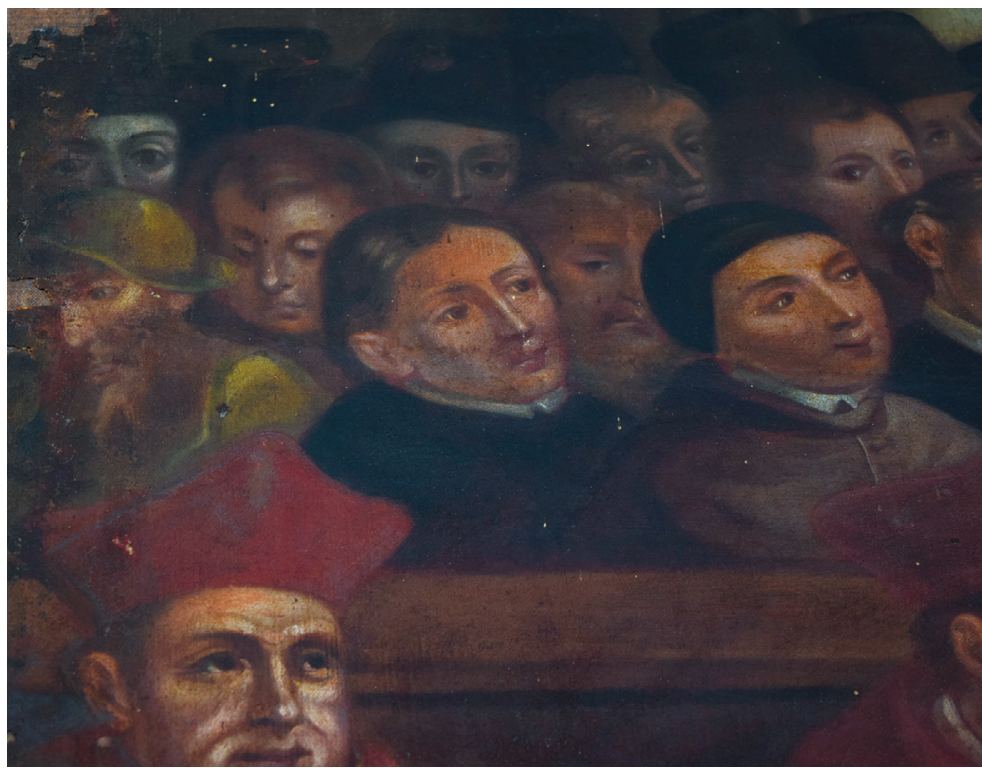

II. Detalle del soldado. Antonio Enríquez, San Ángel carmelita predicando en la basílica de San Juan de Letrán. (C) Alena Robin. SECRETARÍa DE CULtura-INAHMÉx. "Reproducción autorizada por el Instituto Nacional de Antropología e Historia”.

acontecimientos importantes de la vida del santo y de su muerte. El civil con espada podría ser otro personaje que se relaciona con el martirio del santo, el infiel Berengario, quien atacó al carmelita con este tipo de arma (fig. 8). Quisiera proponer que el personaje civil, al lado de los cardenales, vestido con su capa azul, quien se distingue por su centralidad en la composición del lado derecho del cuadro, podría relacionarse más bien con el contexto local de Guadalajara y fuese un retrato de Felipe Pastor, de quien me ocuparé más adelante (fig. 6).

Durante la intervención del cuadro en la ECRO, la limpieza crítica permitió una observación detenida que dio pautas para apreciar la técnica de factura del pintor y destacar ciertos modos de obrar enfocados a cubrir grandes espacios de manera económica. ${ }^{37}$ Por ejemplo, desde antes de empezar con las

37. Agradezco a Gilda Pasco y los alumnos del Seminario-Taller de Restauración de Pintura de Caballete de la ECRO haberme compartido sus hallazgos en varias comunicaciones personales y visitas al taller, así como el reporte de la temporada del mismo, "Proyecto de restauración de la obra San Ángel carmelita predicando en la basilica de San Juan de Letrán" (Guadalajara: 
labores de limpieza crítica, se observó un grado de oxidación diferente en zonas bien delimitadas, lo que levantó la hipótesis de que era una manera intencional de trabajo de Enríquez, lo cual se confirmó con posterioridad. El pintor aplicó el barniz de manera puntual y heterogénea: los colores claros los barnizaba con capas gruesas en donde quería acentuar sombras y no barnizaba o aplicaba capas muy delgadas en los colores oscuros. Así, resaltaba ciertas texturas y dotaba de brillo y luz algunos detalles de mayor importancia, como los rostros y las vestimentas de personajes principales, como el papa y los cardenales. Hay también mucha base de preparación expuesta, por lo que se podría considerar que Enríquez dejaba áreas de reserva. Es decir, no dibujaba los contornos de las formas, sino que dejaba la base de preparación expuesta, dejaba sin cubrir los contornos para dar los acabados a las formas, probablemente con la finalidad de delimitar figuras sin añadir pigmentos, y así ahorrar materiales. Estas zonas se encuentran sobre todo en facciones de caras y manos de personajes secundarios, dentro de la muchedumbre que escucha la predicación del santo carmelita. Así, como propusieron los integrantes del Seminario-Taller de Restauración de Pintura de Caballete de la ECRO en el informe, Enríquez estaría siguiendo una tradición técnica que también se identificó en la obra de Juan Correa. ${ }^{38}$ Asimismo, los rostros los hizo a partir de la aplicación de colores claros para hacer las luces y los volúmenes y deja expuesta la base de preparación en zonas de sombras. De la misma manera, se observó la construcción de ciertas secciones a partir de veladuras, colores muy diluidos, es decir aplicando pintura con poco pigmento, pero abarcando una gran superficie. Por otro lado, se logró apreciar el contraste en la ejecución de los personajes principales como lo son san Ángel, san Francisco, santo Domingo, el papa y los cardenales en su nivel de detalle y atención de rendimiento, en comparación con el grupo de espectadores laicos y eclesiásticos que conforman el público de la predicación del santo carmelita. En estas partes, la atención a la ejecución de las veladuras y las pinceladas es distinta. Este trabajo menos preciso se puede explicar de diferentes maneras, entre ellas por tratarse de zonas de menor atención, que podrían también ser obra del taller. Ciertas irregularidades en la

Escuela de Conservación y Restauración de Occidente-Licenciatura en Restauración de Bienes Muebles-Seminario-Taller de restauración, junio 2019).

38. Elsa Arroyo Lemus y Pablo F. Amador Marrero, "Aproximación a los materiales y las técnicas del pintor Juan Correa”, en Elisa Vargaslugo, Juan Correa. Su vida y su obra, t. I (Ciudad de México: Universidad Nacional Autónoma de México-Instituto de Investigaciones Estéticas, 2017), 222-223. 
superficie permiten pensar que el cuadro sufrió una limpieza anterior, aunque no resulta del todo claro cuándo y en qué contexto se realizó. ${ }^{39}$

\section{Felipe Pastor}

Como consta en la inscripción a los pies del personaje vestido con túnica blanca, de pie, del lado derecho del lienzo, viendo hacia el espectador, señalándose a sí mismo, el cuadro fue patrocinado por Felipe Pastor (figs. 4 y 8). Felipe Pastor Gil de Araguzo era oriundo de Quintanilla de la Mata en los Reinos de Castilla. ${ }^{40}$ Se casó en 1743 con dońa María Isabel de Argomaniz con la cual no tuvo hijo alguno. Felipe Pastor fue un personaje que se asocia con el comercio y la minería en Nueva Galicia. Aparece registrado en agosto de 1746 como "vecino y minero en el Real de San Antonio Tepec", a poca distancia del Real de Bolańos. ${ }^{41}$ Un documento de 1752 alude a Felipe Pastor como "persona de notorio caudal”. ${ }^{42}$ En Guadalajara actuó como alcalde ordinario de primer voto en el

39. La ECRO tiene la intención de realizar un análisis y estudio más profundo sobre estos puntos, pero también de algunos colores, por ejemplo, el negro que se sospecha fue betún de Judea, en la capa de santo Domingo, y para los verdes en la alfombra posiblemente empleó resinato de cobre. También se piensa que Enríquez empleó varios azules en la composición del santo carmelita, y se quisiera comprobar o descartar el uso del índigo.

40. AHJ, Notario Ignacio de la Sierra, vol.ıa: I766-I768, s. f., I7 de abril de 1766.

4I. Archivo del Registro Público de la Propiedad de Guadalajara, Hipotecas, vol. 2, f. 32, 1746, citado en: David Carbajal López, La minería en Bolaños, I748-I8Io (Zamora: El Colegio de Michoacán, 2002), 53. En 1745, Felipe Pastor ofrece 300 pesos a la familia de Francisco Barranco por una mina en Bolaños, transacción que no prosperó. Lo curioso del documento es que no se especifica quién fue Felipe Pastor, por lo cual se puede considerar que era un personaje conocido del medio. Véase Álvaro López Miramontes, "El establecimiento del Real de Minas de Bolaños", Historia mexicana XXIII, núm. 3 (1974): 4I8, y AGN, Tierras, vol. 770, 2a parte, exp. 2, ff. 75r-82v. También se sabe que Felipe Pastor se asoció en mayo de 1758 con Francisco de Ayza para la extracción de plata en explotaciones de la zona, véase ARAG, Civil, I754-1759, caja 59, exp. 5, progresivo 750, ff. 52r-52v, citado en: Carbajal, 89. Algunas de las actividades comerciales de Felipe Pastor están registradas en: AGN, Indiferente General, caja I845, exp. I2, f. 2II, 5 de abril 1762. Agradezco la paleografía de este documento a Iván Baruj Vázquez Clavellina. El expediente está conformado por correspondencia comercial, con memorias de datas, ventas, cuentas e información sobre el traslado de productos en navíos y en la feria de Xalapa en los ańos I76I-1762. El inventario de los bienes que dejó Felipe Pastor a su muerte, incluyendo la descripción y avalúo de los géneros de mercancías existentes en su tienda, se encuentran en: ARAG, Bienes de difuntos, caja 260, exp. 3, progresivo 2849, 1766.

42. AHJ, Notario Blas Silva, Io de enero de 1752. 
cabildo, un puesto importante en el cabildo de la ciudad, en diferentes causas. ${ }^{43}$ También se sabe que recibió el título de coronel de las compañías de infantería milicianas de la ciudad de Guadalajara en junio de $1763 .{ }^{44} \mathrm{El}$ I7 de abril de I766, al momento de hacer su poder para testar, declaró ser hermano profeso de la tercera orden de San Francisco, y pidió ser amortajado con el hábito seráfico; no se indica una relación especial con los carmelitas, como lo sugiere el cuadro de san Ángel predicando.45 Murió el 22 de mayo de 1766 y fue sepultado en la iglesia de La Merced. ${ }^{46}$ De estos documentos, resulta claro que Felipe Pastor fue una figura importante en Guadalajara, en diferentes aspectos. Lo que no queda claro todavía es el contexto en el que patrocinó esta obra pictórica, antes de los múltiples ascensos que conoció en los ámbitos minero y comercial, y sus nombramientos municipales y militares.

\section{Historia reciente del cuadro}

El cuadro ha conocido una multitud de títulos que han oscurecido su apreciación. En el Inventario de 193I de la colección del Museo, Abelardo Carrillo y Gariel registró la obra como Santo Domingo predicando a la nobleza.$^{47}$ En efecto, un cuadro con esta iconografía existe en las colecciones del Museo, pero es obra del pintor dieciochesco José de Ibarra (I685-1756) y proviene del convento dominico de monjas de Santa María de Gracia. ${ }^{48}$ Tal vez esta confusión se deba a las prisas del momento y a la cantidad de obras que se debían registrar al establecer el inventario del Museo Regional de Guadalajara. Por otro lado, la escasa

43. ARAG, Civil, caja 328, exp. 9, progresivo 4720, 1755, y Civil, caja 260, exp. 3, progresivo 2849, 1756.

44. AGN, General de parte, vol. 47, exp. I66, ff. $89 \mathrm{r}$ y v.

45. AHJ, Notario Ignacio de la Sierra, vol. Ia, I766-1768, I7 de abril de I766, s. f.

46. Archivo del Sagrario Metropolitano, Defunciones, 1759-1782, consultado en Family Search, el 27 de mayo de 20I6, consultado el 29 de mayo de 20I6, en https:/familysearch.org/ pal:/MM9.3.I/TH-I-I8380-494I2-35?cc=I87459I. Agradezco a Iván Baruj Vázquez Clavellina la localización de este documento.

47. Inventario de 1931, p. 4, núm I7. La información quedó registrada de la siguiente forma: "Santo Domingo de Guzmán predicando a la nobleza, 'Antonio Enriquez me fecit, año I747", firmado inferior izquierdo. A devoción de Dn. Felipe Pastor. Figuras de cuerpo entero. Dos cuadros que se complementan. Óleo lienzo con bastidor." Esta última anotación sugiere que la composición estaba en ese momento aún con bastidor, y la composición estaba montada en dos secciones separadas.

48. Inventario de I931, p. 30, núm. I36. 
representación de la iconografía en torno a san Ángel carmelita en la Nueva España, la presencia de santo Domingo, así como la multitud de gente escuchando la predicación podrían haber sido motivo de la confusión. Este título fue retomado por Manuel Toussaint, lo cual plantea la pregunta de si Toussaint realmente vio el cuadro o si tomó su información del Inventario de 1931. ${ }^{49}$ Por su parte, Leopoldo Orendáin propuso el título de San Ángel predicando en el Concilio de Letrán. ${ }^{\circ}$ Si bien este título es más cercano a lo representado en la composición de Antonio Enríquez, tampoco es del todo correcto: cuando san Ángel predicó en Roma fue efectivamente en la basílica de San Juan de Letrán, pero no durante un concilio. ${ }^{\text {II }}$ El título con el cual está hoy registrada la obra, Escena religiosa advocación $d t d n$ Felipe Pastor, se debe a una de las inscripciones que ostenta el cuadro, a los pies del personaje vestido con túnica blanca, en el primer plano del lado derecho (fig. 4)..$^{52}$ Sin embargo, esta inscripción hace alusión a quien patrocinó el cuadro, no ayuda a la identificación de la escena representada. Por tanto, se propone un nuevo título: San Ángel carmelita predicando en la basílica de San Juan de Letrán que es más específico de lo que acontece en la pintura.

La pintura se integró al acervo constitutivo del Museo Regional de Guadalajara en 1926. El Inventario de 1931 del Museo establece la pintura procedente del convento de Santa Teresa de Guadalajara. ${ }^{33}$ No obstante, por el tenor de la composición, es más probable que en un inicio fuera de la rama varonil de los carmelitas y que cuando la orden masculina fue suprimida en I86I, este

49. Toussaint, Arte colonial en México, I77; Toussaint, Pintura colonial en México, I87.

50. Orendáin, Pintura. Siglos XVI, XVII y XVIII, 25, 57. Orendáin no hace alusión alguna a la existencia de bastidores.

5I. Hubo cinco concilios de la Iglesia en la basílica de San Juan de Letrán que son conocidos por el nombre del lugar en que se realizaron (II22-II23, II39, II79, I2I5, I5I2-I5I7), pero ninguno coincidió en la presencia de san Ángel carmelita en Roma en I218.

52. Inventario 1993, t. 3. La obra también quedó registrada en el Inventario de 1973-1976, pero sin autor ni título, sólo con una pequeña fotografía de contacto. Se agrega el comentario de que el cuadro estaba "roto y pegado". Lo curioso es que no se contempló la restauración del mismo en la época de conservación de obras que se dio en el Museo Regional de Guadalajara como parte del proyecto de reestructuración de las colecciones, véase Norma Andrea Sánchez González, "La restauración de la Pinacoteca Virreinal del Museo Regional de Guadalajara durante el proyecto de reestructuración I973-1976. Principios, criterios y técnicas de intervención en la pintura sobre lienzo", tesis de Licenciatura (Guadalajara: Escuela de Conservación y Restauración de Occidente, 2015).

53. Inventario I931, 4, núm. I7. 
cuadro, con otros bienes de los carmelitas, pasara a formar parte del patrimonio de las monjas de Santa Teresa. De hecho, en el inventario que se levantó a raíz de la supresión del convento masculino se menciona, sin confirmar en qué espacio de la iglesia o convento se encontraba, "un cuadro grande maltratado: un grupo figurando en primer término un santo vestido de casulla, sin marco", que, por la descripción, podría tratarse del cuadro que nos ocupa. ${ }^{54}$ Es de subrayar que se menciona que la pintura estaba maltratada y sin marco.

Queda muy poco del esplendor original del convento masculino de carmelitas descalzos. 55 Fray Luis del Refugio Palacio describió la iglesia de los carmelitas como "un Escorial en miniatura" debido a la riqueza de su ornamentación, pero no alude al cuadro de Enríquez en específico. ${ }^{56}$ Por las dimensiones y el patrocinio del cuadro, se puede suponer que la obra estuviese a la vista del público, tal vez en una capilla lateral de la iglesia.

La obra presentaba varios deterioros de distinta índole. Se desconoce cuándo se realizó la eliminación total del bastidor, pero puede explicarse por un ataque de insectos. Así lo demuestran las perforaciones en el textil en zonas que coincidieron con el bastidor. La eliminación del bastidor también pudo deberse a la necesidad de almacenamiento en un espacio reducido, así como para facilitar el transporte de los lienzos en forma enrollada. Hay otras intervenciones de carácter estructural y estético realizadas mientras la obra aún conservaba sus bastidores. ${ }^{57}$ Las intervenciones que presentaba la obra eran antiguas y tuvieron como propósito otorgar mayor resistencia a los grandes lienzos, así como

54. AHAG, Gobierno, religiosos, carmelitas varones, I743-I838, exp. 8, caja I, f. 3 r.

55. Resulta muy interesante un opúsculo escrito hacia finales de 1863 que describe el estado lamentable del convento en ese momento. Véase "Recuerdos del Carmen de Guadalajara”, Boletín Eclesiástico de la Arquidiócesis de Guadalajara, julio de 2007. El original se publicó en I864 por la imprenta de Dionisio Rodríguez. Agradezco al padre Tomás de Híjar haberme informado sobre la existencia de este opúsculo.

56. Luis del Refugio de Palacio, Recopilación de noticias y datos que se relacionan con la milagrosa imagen de Nuestra Señora de Zapopan y con su colegio y santuario, t. I (Guadalajara: Universidad de Guadalajara, 1942), 246. Algunas obras destacadas que aún pertenecen al templo carmelita en Guadalajara son un fragmento de la Pasión de Cristóbal de Villalpando, un San José y un San Antonio atribuidos a Miguel Cabrera, y un Santo Tomás de Aquino, atribuido a José de Ibarra. Véase Jaime Abundis Canales, La huella Carmelita en San Ángel, vol. II (Ciudad de México: Instituto Nacional de Antropología e Historia, 2007), I215.

57. Óscar Antonio García Rodríguez, "Proyecto de restauración de la pintura titulada El abrazo de san Ángel, santo Francisco y santo Domingo perteneciente a la pinacoteca del Museo Regional de Guadalajara”, febrero de 2016. 
disminuir el efecto producido por las roturas y alteraciones de la capa pictórica. Los tratamientos fueron puntuales y no involucraron limpiezas profundas, repintes extensivos, ni rebarnizados. Estos tratamientos cumplieron con su objetivo en su momento, pero hasta hace poco se encontraban en proceso de desprendimiento, y los repintes se observaban como manchas empastadas y opacadas de colores muy distintos al original.

El inventario de 193I registra que la pintura está compuesta de "dos cuadros que se complementan", y así pasó a constituir parte de las colecciones del Museo Regional de Guadalajara en la forma en que actualmente se encuentra: seccionada a la mitad, en dos partes. El cuadro recibió en tiempo reciente tratamientos de consolidación, conservación y restauración en la Escuela de Conservación y Restauración de Occidente. Estos procedimientos con seguridad arrojarán nueva información sobre el cuadro, y una más completa apreciación de esta obra desconocida de la pintura novohispana. \$ 